\title{
Botulinum neurotoxin in neurological practice - a leading topic in neurology
}

\author{
Jarosław Sławek ${ }^{1,2}$, Wolfgang H. Jost ${ }^{3}$ \\ ${ }^{1}$ Division of Neurological and Psychiatric Nursing, Faculty of Health Sciences, Medical University of Gdansk, Poland \\ ${ }^{2}$ Department of Neurology and Stroke, St. Adalbert Hospital, Gdansk, Poland \\ ${ }^{3}$ Parkinson-Klinik Ortenau, Wolfach, Germany
}

Key words: botulinum neurotoxin, dystonia, spasticity, migraine, neuropathic pain

(Neurol Neurochir Pol 2021; 55 (2): 120-124)

In this issue of the Polish Journal of Neurology and Neurosurgery, we introduce a new form of publication of collected papers regarding one topic. This we call a 'leading topic'. As guest editors of this special series of papers, we would like to present selected papers regarding botulinum neurotoxin (BoNT) treatment in neurology.

Botulinum neurotoxin is a leading treatment option in many indications in neurology such as focal/segmental dystonias (blepharospasm, Meige syndrome, cervical dystonia, writer's cramp or spasmodic dysphonia), spasticity in children (cerebral palsy) and adults (post-stroke), overactive bladder, chronic migraine or hyperhidrosis and siallorhea (Tab. 1). The list of as-yet unlicensed or off-label indications is long and some examples will be discussed (Tab. 2). A PubMed database search using the key word 'Botulinum toxin' found 10,568 records at the end of March 2021, making this treatment option a leading topic in neurology.

There are three major botulinum neurotoxin type-A preparations according to the FDA (the US Food \& Drug Administration) requirements: onabotulinumtoxinA (ONA-BoNT/A), abobotulinumtoxinA (ABO-BoNT/A), and incobotulinumtoxin A (INCO-BoNT/A). These have the trade names Botox ${ }^{\oplus}$, Dysport ${ }^{\oplus}$ and Xeomin ${ }^{\oplus}$ respectively. Botulinum neuroxin type B (rhimabotulinumtoxinB) with the trade name Myobloc/Neurobloc ${ }^{\oplus}$ was intended to be used in secondary unresponsiveness to type-A with the formation of neutralising antibodies. The efficacy and safety of BoNT/A and $\mathrm{B}$ have been positively assessed and rated at level A or B (for different indications and preparations) by the American Academy of Neurology in its Task Force guidelines [1]. Their effectiveness has been confirmed in many open-label studies including ones also published in this journal, and indeed in this issue [2-5].

However, although this treatment has been offered to patients for the last 30 years, many unresolved problems and unmet needs remain.. One of them is the inability to make a direct comparison in terms of efficacy and the lack of a universal dose-ratio between different products. In two papers published in this issue, we have reviewed both the basic [6] and the clinical $[7,8]$ research in terms of bioequivalence of currently available preparations in major indications. Many of them are indirect, showing the overall results achieved with pre-established doses of different preparations. Direct comparisons were made difficult because of pre-fixed ratios, different methodologies, and the relatively low quality of studies.

We have concluded that universal ratios between products cannot be therefore established. Methods of assessment of clinical efficacy differ between companies. Also the methodologies of studies published so far has been rather poor, based on laboratory or electrophysiological methods in healthy volunteers or small groups of patients. This is especially important, because new BoNT/A fomulations (e.g. daxibotulinumtoxinA, prabotulinumtoxin $\mathrm{A}$ ) are now in clinical trials, and therefore a switch between products in future might be even more difficult. Switching from one preparation to another is common in clinical practice, as shown in many open label studies with long follow ups. Lengthy treatment is a risk factor for the formation of neutralising antibodies, and therefore treatment regimens should respect optimal (not maximal) doses and intervals between injections [9].

Address for correspondence: Jarosław Sławek, MD, PhD, Department of Neurology and Stroke, St. Adalbert Hospital, Al. Jana Pawła II 50 Str., $80-462$ Gdansk, Poland, e-mail: jaroslaw.slawek@gumed.edu.pl 
Table 1. Licensed indications for BoNT/A in neurology and beyond (according to SPCs for all three types of BoNT/A) [36-38]

\begin{tabular}{|c|c|c|c|}
\hline Indication & ONA-BoNT/A & ABO-BoNT/A & INCO-BoNT/A \\
\hline Cervical dystonia & + & + & + \\
\hline Blepharospasm & + & + & + \\
\hline Strabismus ( $>5 y$ rs old) & + & - & - \\
\hline Hemifacial spasm & $t^{*}$ & + & + \\
\hline Upper limb spasticity (post-stroke) & + & + & + \\
\hline Lower limb spasticity (post-stroke) & + & + & - \\
\hline Spasticity in cerebral palsy (upper limbs) & + & + & - \\
\hline Spasticity in cerebral palsy (lower limbs) & + & + & - \\
\hline Overactive bladder & + & - & - \\
\hline $\begin{array}{l}\text { Detrusor hyperactivity in neurological conditions (MS, SCI) and } \\
\text { paediatric patients }>5 \mathrm{yrs} \text { old }\end{array}$ & + & - & - \\
\hline Sialorrhea & - & - & + \\
\hline Hyperhidrosis (axillary) & + & + & - \\
\hline Chronic migraine & + & - & - \\
\hline
\end{tabular}

MS - multiple sclerosis; SCI — spino-cerebral injury; * not present in US SPC.

For ONA-BoNT/A the term 'Blepharospasm, hemifacial spasm and other associated dystonias' is used in SPC. Therefore, there is no specific indication for laryngeal dystonia or oromandibular dystonia

Table 2. Off-label indications for BoNT/A in neurology and beyond [26, 29, $32,34,35,39-41]$

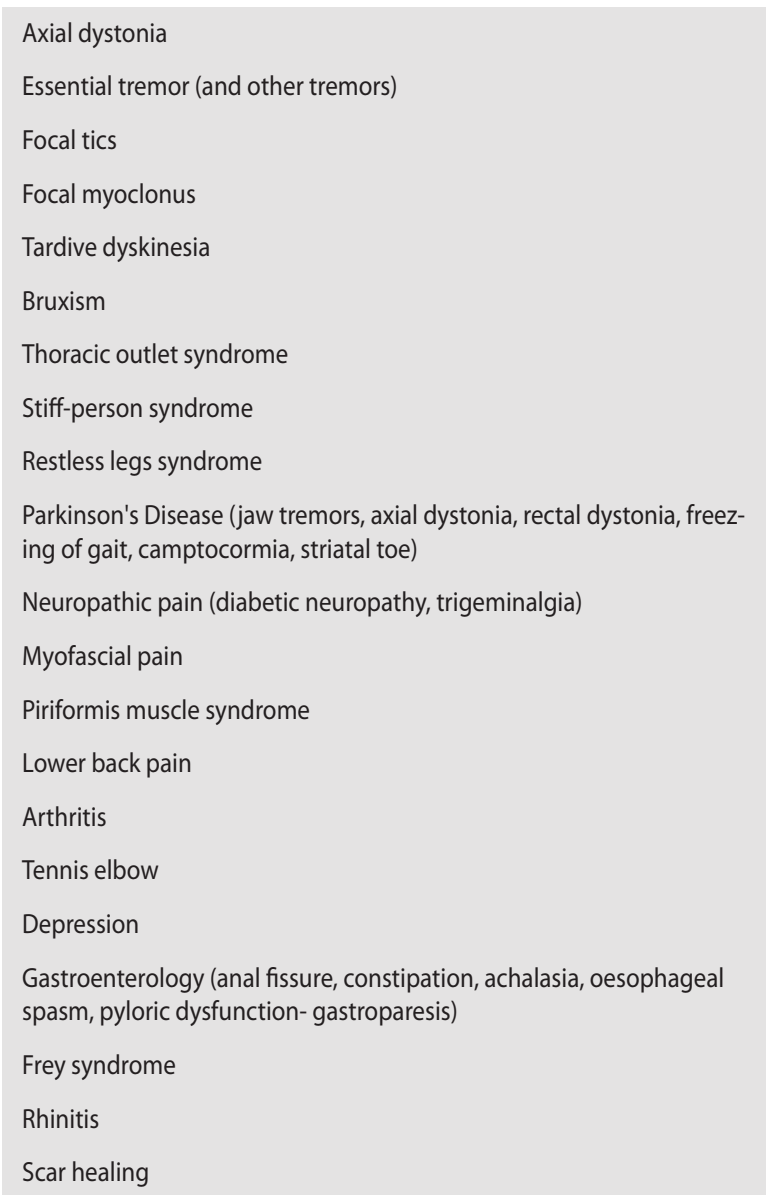

In conclusion, we should respect the specific doses recommended in the summary product characteristics of specific BoNT/A medications and take into consideration the dose modifiers as being body and muscle mass, dysphagia, and dyspnoea. In spasticity, treatment has to be adjusted to functional impairment: if function is preserved, the dose should be decreased.

Cervical dystonia $(\mathrm{CD})$ remains the most challenging indication due to its complexity and the need for life-long treatment. The wide spectrum of motor and non-motor problems (recognised in recent years) was discussed also in our journal in $2020[10,11]$ and now we continue this topic in this issue $[5,12,13]$. We emphasise the unmet needs for this kind of treatment: the as yet not widely used or accepted Col-Cap concept and the most frequent patterns,the lack of specific scales for this new classification, the need for standardised ultrasound/ /electromyographical guided injections (and scientific proof that they really are superior to anatomical landmarks), and the lack of standardised treatments of non-motor symptoms. The doses of BoNT/A in CD and spasticity were arbitrarally established in clinical trials. In this issue, an international group of authors present the results of a multicentre study showing real-life treatment where doses were lower than in published guidelines, presumably due to more precise injections under US guidance [13]. As there have been no studies published so far looking for the optimal dose per muscle, this is perhaps not the best, but still a valuable, way of showing the effectiveness of doses used in clinical practice in experienced centres. The choice of muscle should be adjusted to the specific pattern of CD. The number of involved muscles varies, usually between four and six. 
We should respect the maximal dose in the summary product characteristics of all three BoNT/A preparations [14, 15].

Muscle hypertonia in cerebral palsy has been a licensed indication for BoNT/A for the last 25 years. The authors of the evidence-based review on efficacy and safety published in this issue have shown that all major BoNT/A preparations have been established to reduce hypertonia in both upper and lower extremities, with some conflicting evidence regarding function. There are no differences in treatment safety, with a low incidence of adverse events which are mostly temporary and mild. Similarly to dystonia and spasticity in adults, there is no universal ratio enabling the calculation of dose when switching between preparations [9].

This long-term treatment is complementary to rehabilitation with the use of physiotherapy, orthotics and casting. Although BoNT/A treatment alone was positively assessed by the American Academy of Neurology and Child Neurology Society [16], almost a decade later there is still scant evidence regarding its comparative treatment with different rehabilitation methods and moderate with placebo [17]. In severe generalised hypertonia, a multilevel approach is recommended by different centres. The unresolved issues are the length of time between injections, the overall time of treatment, and how to define functional improvement. All these unresolved problems are valid also for spasticity in adults. This is usually severe in more pronounced paresis, and therefore functional improvement in the form of the recovery of complex and precise limb movements is usually not possible [18]. Therefore, so-called 'goal-attainment treatment' is now preferred to establish realistic goals with the patients and their care-giver before injection [19]. New studies have focused on early ( $<3$ months) spasticity after stroke and combined treatment with physiotherapy, casting, and orthoses. So far the quality of evidence on combined treatment is low. This early treatment with BoNT is a promising approach, and may decrease the severity of spasticity in the following months or years. In the first three months, the neural component dominates over the biomechanical one with the ability to influence plasticity and central motor learning [20-23]. Nevertheless, it requires further long-term studies to prove the concept.

In chronic migraine $(\mathrm{CM}), \mathrm{BoNT} / \mathrm{A}$ therapy is now an established and licensed indication (exclusively for ONA-BoNT/A after the successful PREEMPT studies). Nevertheless, new licensed and emerging biological therapies with anti-CGRP anibodies (mAbs such as erenumab, fremanezumab, galcanezumab etc) have given rise to the problem of how to position them in clinical practice and reimbursement systems. There are no head-to-head studies between $\mathrm{mAbs}$ and BoNT/A. Those pivotal studies performed to license mAbs also differed in methodology with BoNT/A studies. Therefore, positioning should be based on indirect comparisons, expert consensus, and pharmacoeconomic considerations. Further comparative studies are needed.

The spectrum of potential clinical indications for BoNT is still growing, with treatment of sialorrhea being a newly licensed indication (exclusively for INCO-BoNT/A) [24]. There is also a growing number of so-called 'off-label indications' such as: essential tremor (the systematic review published recently in our journal suggests that improvement is usually biased by muscle weakness) [25], focal tics, myoclonus, bruxism [26], neuropathic pain (due to diabetic or postherpetic neuropathy and of central origin) $[27,28]$ or even depression [29].

Not strictly neurological, but helpful in our patients' indications (published earlier, but discussed also in this issue) is megacolon following a stroke and successfully treated with BoNT/A [30,31]. Botulinum toxin is used also in other gastroenterological indications for the treatment of anal fissure, constipation (puborectal muscle) in Parkinson's Disease or achalasia and many other conditions, along with cosmetic purposes (e.g. to remove frown lines, wrinkles) that are not discussed here (Tab. 2) [32-35].

Botulinum toxin over the last 30 years has changed the treatment modalities in many neurological disorders or symptoms. We hope and believe that the story is not over.

Conflicts of interest: Both authors have lectured and consulted for Merz, Ipsen and Allergan.

\section{References}

1. Simpson DM, Hallett M, Ashman EJ, et al. Practice guideline update summary: Botulinum neurotoxin for the treatment of blepharospasm, cervical dystonia, adult spasticity, and headache: Report of the Guideline Development Subcommittee of the American Academy of Neurology. Neurology. 2016; 86(19): 1818-1826, doi: 10.1212/WNL.0000000000002560, indexed in Pubmed: 27164716.

2. Sarzyńska-Długosz I, Szczepańska-Szerej A, Drużdż A, et al. Real-world effectiveness of abobotulinumtoxinA (Dysport ${ }^{\circledR}$ ) in adults with upper limb spasticity in routine clinical practice: an observational study. Neurol Neurochir Pol. 2020; 54(1): 90-99, doi: 10.5603/PJNNS. a2020.0004, indexed in Pubmed: 31956971.

3. Esquenazi A, Bavikatte G, Bandari DS, et al. Long-Term Observational Results from the ASPIRE Study: OnabotulinumtoxinA Treatment for Adult Lower Limb Spasticity. PM R. 2020 [Epub ahead of print], doi: 10.1002/pmrj.12517, indexed in Pubmed: 33151636.

4. Harriss J, Roche N, Cantú-Brito C, et al. Spasticity in practice (SPACE): an international non-interventional study of botulinum neurotoxin type A in treatment-naïve subjects with spasticity. Neurol Neurochir Pol. 2021; 55(2): 165-173, doi: 10.5603/PJNNS.a2021.0001, indexed in Pubmed: 33433902.

5. Sławek J, Jost WH. Botulinum neurotoxin in cervical dystonia revisited - recent advances and unanswered questions. Neurol Neurochir Pol 2021; 55(2): 125-132, doi: 10.5603/PJNNS.a2021.0029, indexed in Pubmed: 33822352.

6. Car H, Bogucki A, Bonikowski M, et al. Botulinum toxin type-A preparations are not the same medications - basic science (Part 1). Neurol Neurochir Pol 2021; 55(2): 133-140, doi: 10.5603/PJNNS. a2021.0027, indexed in Pubmed: 33797747.

7. Sławek J, Bogucki A, Bonikowski M, et al. Botulinum toxin type-A preparations are not the same medications - clinical studies (Part 2). 
Neurol Neurochir Pol. 2021; 55(2): 141-157, doi: 10.5603/PJNNS. a2021.0028, indexed in Pubmed: 33797748.

8. Bonikowski M, Sławek J. Safety and efficacy of Botulinum toxin type A preparations in cerebral palsy - an evidence-based review. Neurol Neurochir Pol 2021; 55(2): 158-164, doi: 10.5603/PJNNS. a2021.0032, indexed in Pubmed: 33861462.

9. Hefter H, Hartmann $\mathrm{CJ}$, Kahlen U, et al. Clinical Improvement After Treatment With IncobotulinumtoxinA (XEOMIN®) in Patients With Cervical Dystonia Resistant to Botulinum Toxin Preparations Containing Complexing Proteins. Front Neurol. 2021; 12: 636590, doi: 10.3389/ fneur.2021.636590, indexed in Pubmed: 33633680.

10. Tyślerowicz M, Kiedrzyńska W, Adamkiewicz B, et al. Cervical dystonia - improving the effectiveness of botulinum toxin therapy. Neurol Neurochir Pol. 2020; 54(3): 232-242, doi: 10.5603/PJNNS.a2020.0021, indexed in Pubmed: 32285434.

11. Pena AB. Botulinum toxin for cervical dystonia: addressing treatment failure and improving outcomes. Neurol Neurochir Pol. 2020; 54(3): 218-219, doi: 10.5603/PJNNS.2020.0047, indexed in Pubmed: 32602934.

12. Slawek J, Friedman A, Potulska A, et al. Factors affecting the health-related quality of life of patients with cervical dystonia and the impact of botulinum toxin type A injections. Funct Neurol. 2007; 22(2): 95-100, indexed in Pubmed: 17637212.

13. Jost WH, Drużdż A, Pandey S, et al. Dose per muscle in cervical dystonia: pooled data from seven movement disorder centres. Neurol Neurochir Pol. 2021; 55(2): 174-178, doi: 10.5603/PJNNS.a2021.0005, indexed in Pubmed: 33471347.

14. Jost WH, Biering-Sørensen Bo, Drużdż A, et al. Preferred muscles in cervical dystonia. Neurol Neurochir Pol. 2020; 54(3): 277-279, doi: 10.5603/PJNNS.a2020.0022, indexed in Pubmed: 32227332.

15. Jost WH, Tatu L, Pandey S, et al. Frequency of different subtypes of cervical dystonia: a prospective multicenter study according to Col-Cap concept. J Neural Transm (Vienna). 2020; 127(1): 45-50, doi: 10.1007/s00702-019-02116-7, indexed in Pubmed: 31828512.

16. Delgado MR, Hirtz D, Aisen M, et al. Quality Standards Subcommittee of the American Academy of Neurology and the Practice Committee of the Child Neurology Society. Practice parameter: pharmacologic treatment of spasticity in children and adolescents with cerebral palsy (an evidence-based review): report of the Quality Standards Subcommittee of the American Academy of Neurology and the Practice Committee of the Child Neurology Society. Neurology. 2010; 74(4): 336-343, doi: 10.1212/WNL.0b013e3181cbcd2f, indexed in Pubmed: 20101040.

17. Blumetti FC, Belloti JC, Tamaoki MJs, et al. Botulinum toxin type A in the treatment of lower limb spasticity in children with cerebral palsy. Cochrane Database Syst Rev. 2019 [Epub ahead of print]; 10: CD001408, doi: 10.1002/14651858.CD001408.pub2, indexed in Pubmed: 31591703.

18. Schinwelski MJ, Sitek EJ, Wąż P, et al. Prevalence and predictors of post-stroke spasticity and its impact on daily living and quality of life. Neurol Neurochir Pol. 2019; 53(6): 449-457, doi: 10.5603/PJNNS. a2019.0067, indexed in Pubmed: 31845749.

19. Jost WH, Hefter H, Reissig A, et al. Efficacy and safety of botulinum toxin type A (Dysport) for the treatment of post-stroke arm spasticity: results of the German-Austrian open-label post-marketing surveillance prospective study. J Neurol Sci. 2014; 337(1-2): 86-90, doi: 10.1016/j.jns.2013.11.022, indexed in Pubmed: 24361062.
20. Patel AT, Ward AB, Geis C, et al. Impact of early intervention with onabotulinumtoxinA treatment in adult patients with post-stroke lower limb spasticity: results from the double-blind, placebo-controlled, phase 3 REFLEX study. J Neural Transm (Vienna). 2020; 127(12): 1619-1629, doi: 10.1007/s00702-020-02251-6, indexed in Pubmed: 33106968.

21. Demetrios M, Khan F, Turner-Stokes L, et al. Multidisciplinary rehabilitation following botulinum toxin and other focal intramuscular treatment for post-stroke spasticity. Cochrane Database Syst Rev. 2013(6): CD009689, doi: 10.1002/14651858.CD009689.pub2, indexed in Pubmed: 23740539.

22. Li S. Spasticity, Motor Recovery, and Neural Plasticity after Stroke. Front Neurol. 2017; 8: 120, doi: 10.3389/fneur.2017.00120, indexed in Pubmed: 28421032.

23. Hok P, Veverka T, Hluštík $P$, et al. The Central Effects of Botulinum Toxin in Dystonia and Spasticity. Toxins (Basel). 2021; 13(2), doi: 10.3390/toxins13020155, indexed in Pubmed: 33671128.

24. Jost WH, Friedman A, Michel O, et al. SIAXI: Placebo-controlled, randomized, double-blind study of incobotulinumtoxinA for sialorrhea. Neurology. 2019; 92(17): e1982-e1991, doi: 10.1212/ WNL.0000000000007368, indexed in Pubmed: 30918101.

25. Zheng $X$, Wei W, Liu P, et al. Botulinum toxin type A for hand tremor: a meta-analysis of randomised controlled trials. Neurol Neurochir Pol. 2020; 54(6): 561-567, doi: 10.5603/PJNNS.a2020.0079, indexed in Pubmed: 33047784.

26. Anandan C, Jankovic J. Botulinum Toxin in Movement Disorders: An Update. Toxins (Basel). 2021; 13(1), doi: 10.3390/toxins13010042, indexed in Pubmed: 33430071.

27. Egeo G, Fofi L, Barbanti P. Botulinum Neurotoxin for the Treatment of Neuropathic Pain. Front Neurol. 2020; 11: 716, doi: 10.3389/ fneur.2020.00716, indexed in Pubmed: 32849195.

28. Lakra C, Cohen H. A clinical review of the use of Botulinum Toxin type $A$ in managing central neuropathic pain in patients with spinal cord injury. J Spinal Cord Med. 2020 [Epub ahead of print]: 1-5, doi: 10.1080/10790268.2020.1848278, indexed in Pubmed: 33263489.

29. Schulze J, Neumann I, Magid M, et al. Botulinum toxin for the management of depression: An updated review of the evidence and meta-analysis. J Psychiatr Res. 2021; 135: 332-340, doi: 10.1016/j. jpsychires.2021.01.016, indexed in Pubmed: 33578275.

30. Nowak P, Gala-Błądzińska A, Stybel K, et al. Botulinum toxin in the treatment of intestinal pseudo-obstruction following a stroke. Neurol Neurochir Pol. 2020; 54(6): 589-590, doi: 10.5603/PJNNS. a2020.0073, indexed in Pubmed: 33026647.

31. Madalinski M. Constipation due to a stroke complicated with pseudo-obstruction (Ogilvie's Syndrome). Neurol Neurochir Pol. 2021; 55(2): 230232, doi: 10.5603/PJNNS.a2021.0003, indexed in Pubmed: 33459344.

32. Sławek J, Madaliński M. Botulinum Toxin Therapy for Nonmotor Aspects of Parkinson's Disease. Int Rev Neurobiol. 2017; 134: 1111-1142, doi: 10.1016/bs.irn.2017.04.012, indexed in Pubmed: 28805566.

33. Madalinski MH, Slawek J. Safety of botulinum toxin therapies. Dis CoIon Rectum. 2003; 46(12): 1719-1720, doi: 10.1007/BF02660785, indexed in Pubmed: 14668605.

34. Madaliński MH, Sławek J, Duzyński W, et al. Side effects of botulinum toxin injection for benign anal disorders. Eur J Gastroenterol Hepatol. 2002; 14(8): 853-856, doi: 10.1097/00042737-20020800000007, indexed in Pubmed: 12172405. 
35. Jost WH. Other indications of botulinum toxin therapy. Eur J Neurol. 2006; 13 Suppl 1: 65-69, doi: 10.1111/j.1468-1331.2006.01448.x, indexed in Pubmed: 16417601.

36. Dysport ${ }^{\circledR}$ (abobotulinumtoxinA) [prescribing information]. Boulogne-Billancourt: IpsenBiopharm Ltd; 2012. Accessed October. ; 8: 2020.

37. Food and Drug Administration (FDA). SpringerReference. , doi: 10.1007/springerreference_32222.

38. Allergan, Ltd. BOTOX® 100 U. Summary of product characteristics [webpage on the Internet]. Surrey, UK: Datapharm Communications Ltd; 2013 [updated December 12, 2012]. http://www.medicines.org. uk/emc/medicine/112 (8 Oct 2010).
39. Brashear A. Botulinum toxin type A: Exploring new indications. Drugs Today (Barc). 2010; 46(9): 671-682, doi: 10.1358/dot.2010.46.9.1524356, indexed in Pubmed: 20967299.

40. Monnier G, Tatu L, Michel F. New indications for botulinum toxin in rheumatology. Joint Bone Spine. 2006; 73(6): 667-671, doi: 10.1016/j.jbspin.2006.03.005, indexed in Pubmed: 16997603.

41. Motz KM, Kim YJ. Auriculotemporal Syndrome (Frey Syndrome). Otolaryngol Clin North Am. 2016; 49(2): 501-509, doi: 10.1016/j. otc.2015.10.010, indexed in Pubmed: 26902982. 